\title{
Entrevistas en auto-confrontación: un método en clínica de la actividad
}

\section{Entrevistas em auto-confrontação: um método em clínica da atividade}

\begin{abstract}
Resumen:
Los actuales métodos de análisis psicológico de las actividades profesionales asocian de forma muy desigual a los protagonistas del trabajo al análisis de su propia actividad. Desde nuestra perspectiva metodológica, procuramos hacer un análisis conjunto con los colectivos de trabajadores. El objetivo que nos guía es el desarrollo del colectivo y de la situación de trabajo. Nuestra experiencia nos ha convencido que solo los trabajadores pueden imponer transformaciones duraderas al trabajo. Desde un punto de vista científico, nuestra tarea, más modesta, pero también más exigente, es apuntalar a los esfuerzos de los colectivos de trabajadores para ampliar su radio de acción. Para ello, utilizamos un método que llamamos de autoconfrontación indirecta (Faïta, 1997). En realidad, además de tratarse de un método de intervención en las situaciones de trabajo, es una metodología de co-análisis porque organiza las relaciones entre los investigadores y los colectivos, tomando como base los enfoques teóricos que a continuación exponemos. Palabras-clave: auto-confrontacion; clinica de la actividad.
\end{abstract}

\section{RESUMO:}

Os atuais métodos de análise psicológica das atividades profissionais associam de forma muito desigual os protagonistas do trabalho à análise de sua própria atividade. Desde nossa perspectiva metodológica, procuramos fazer uma análise conjunta com os coletivos de trabalhadores. 0 objetivo que nos guia é o desenvolvimento do coletivo e da situação de trabalho. Nossa experiência nos tem convencido que só os trabalhadores podem impor transformações duradouras ao trabalho. Desde um ponto de vista científico, nossa tarefa, mais modesta, porém também mais exigente, é apontar os esforços dos coletivos de trabalhadores para ampliar seu raio de ação. Para isto, utilizamos um método que chamamos de autoconfrontação indireta (Faita, 1997). $\mathrm{Na}$ realidade, apesar de tratar-se de um método de intervenção nas situações de trabalho, é uma metodologia de co-análise porque organiza as relações entre os investigadroes e os coletivos, tomando como base os enfoques teóricos que na continuação expomos.

Palavras-chave: auto-confrontação; clínica da atividade.

FERNANDEZ, Gabriel; CLOT, Yves. Entrevistas en auto-confrontación: un método en clínica de la actividad. Informática na Educação: teoria \& prática, Porto Alegre, v. 13, n. 1, p. 11-16, jan./jun. 2010.

\author{
Gabriel Fernández \\ Yves Clot \\ Conservatoire National des Arts et Métiers
}

\section{Actividad realizada y actividad real}

5 clásica la distinción entre tarea y actividad: la tarea es lo prescrito por la organización del trabajo, lo que los trabajadores deben hacer y la actividad es lo que realizan para lograr lo prescrito (LEPLAT; HOC, 1983).

Sin embargo, nuestro trabajo (CLOT, 1995, 1999a, 2007; CLOT; FERNANDEZ, 2000; CLOT; FAÏTA, 2000) nos obliga a considerar que la actividad observada no es más que la actualización de una entre muchas otras posibilidades con las que los trabajadores hubiesen podido cumplir con lo prescrito. Vygotski (1991, p. 47) señala que : "El comportamiento es un sistema de reacciones triunfantes [...]". Asimismo, afirmamos que la actividad realizada es la que triunfó entre otras con las cuales competía. Los conflictos entre todas las actividades posibles son los que, finalmente, determinan el desarrollo de la actividad vencedora.

Esto nos lleva a considerar que la actividad realizada solo es una parte de la actividad real. Lo que uno no hace, porque renuncia o porque no consigue hacerlo, o lo que piensa poder hacer en otro lugar o en otras circunstancias, también forma parte de la actividad. Por consiguiente, un enfoque demasiado cognitivo de la conciencia no da cuenta de lo vitales que son para el sujeto, los conflictos nacidos de su 
actividad real, razón por la cual integramos al análisis psicológico de la actividad las acciones suspendidas o impedidas (CLOT, 1999a).

\section{El género de la actividad: una memoria para actuar}

Es preciso afinar la distinción entre tarea y actividad ya que la oposición entre los dos términos nos es inmediata. En nuestras intervenciones hemos comprobado que existe una continuidad entre la prescripción social y la actividad de los trabajadores. Dicho de otra manera, el colectivo profesional realiza un trabajo de organización que une la actividad de un trabajador con la organización oficial del trabajo. Es una creación sui generis, una transformación de la organización del trabajo que le confiere eficacia. Designamos esta creación como el género social de una profesión, o género profesional. Es un conjunto de obligaciones que, sin proponérselo, impone el grupo profesional para poder alcanzar el objetivo, incluso en contra del modus operandi prescrito. Además, es un conjunto de evaluaciones de las situaciones compartidas por los profesionales, que sirven para organizar de forma implícita su actividad.

Desde el punto de vista del sujeto, es una memoria para la acción. Es una memoria transpersonal y colectiva que le da consistencia a su actividad: maneras de ser, de comportarse, de iniciar y terminar una acción, de dirigir la actividad con éxito. Estas maneras de aobrdar las cosas y de dirigirse a las personas forman un repertorio de actos preorganizados, admitidos o desplazados, producto de la historia del grupo profesional. Berthoz (1997) habla de memoria del futuro. Para nosotros, el género profesional es un entramado de técnicas, tanto del cuerpo como intelectuales, de palabras y de gestos profesionales. Lo consideramos como un recurso que el profesional puede adaptar al contexto de la acción, y con él que también, en la mayoría de las veces, adapta el contexto para actuar.

El género profesional tiene entonces dos caras: por un lado es un conjunto de normas compartidas $y$, por otro lado, un recurso para la vida profesional ya que otorga la posibilidad a cada miembro del colectivo de trabajo de adaptar la norma. Para nosotros, este es un punto determinante de la mobilización subjetiva. El género es un medio para saber como actuar en la situación profesional. Su adopción, conciente o no, por parte del sujeto marca su pertenencia al grupo profesional y orienta su acción. El carácter transpersonal del género le confiere una función psicológica peculiar ya que, sobretodo, organiza las relaciones profesionales entre trabajadores y no directamente las relaciones intersubjetivas entre personas.

\section{El estilo: moderar la obligación para agilizar el desarrollo}

El género profesional tiene entonces un aspecto normativo que le da consistencia y perennidad. $Y$ es por eso que cada miembro del grupo profesional puede acoplarlo a las exigencias de su acción. Esta adaptación hace del género profesional un instrumento de la actividad. Pensamos que el estilo de la acción es el proceso psicológico que le permite al sujeto ajustar el género. El profesional se deshace de ciertas obligaciones genéricas transformándolas, lo que hace posible la continuidad de su acción. Bajo este aspecto, el sujeto interpone entre él y las obligaciones genéricas una distancia psicológicamente necesaria para ajustar la regla, el gesto o la palabra, y de este modo conservarle su propiedad de recurso para la acción. El estilo es, entonces, el proceso que mantiene vivo al género profesional, puesto que lo desarrolla al incluir nuevas variantes valoradas y conservadas -o no-, por el colectivo profesional.

En realidad el estilo realiza una doble liberación. La primera es una liberación con relación a la memoria transpersonal, es decir, como lo acabamos de señalar, la memoria de las obligaciones genéricas. La segunda es con relación a la historia personal. El sujeto ajusta sus propios esquemas personales - sensitivomotores, cognitivos, emocionales-, movilizados en la acción bajo el doble impulso del sentido personal de la actividad y de la eficiencia de las operaciones de trabajo.

También vemos esta segunda liberación como un desarrollo, en este caso del sujeto, que tiene lazos estrechos con su salud. La clínica de las actividades profesionales nos ha enseñado que la estricta conservación del ser es un obstáculo para la salud. Solo el desar- 
rollo del poder de acción sobre el entorno y sobre sí mismo es un factor favorable para la salud. Las defensas que los trabajadores construyen para salvar su normalidad los rebajan (CLOT, 1999b), porque la normalidad no es más que la adopción de una norma única, mientras que la salud responde a la capacidad de producir nuevas normas, incluso en contra de la norma vigente (CANGUILHEM, 1984).

\section{Metodología}

La metodología que utilizamos en nuestras intervenciones tiene un objetivo principal que condiciona todas nuestras acciones: ayudar al desarrollo de la experiencia profesional del colectivo de trabajadores voluntarios. Se suele pensar, con razón, que para transformar una situación es fundamental entenderla. Sin embargo, con frecuencia hemos podido comprobar que para entender una situación es preciso previamente transformarla, siempre que la intención sea ampliar el poder de acción de los colectivos. Utilizamos para nuestras intervenciones un método de autoconfrontación que responde a esta metodología. Se compone de tres fases sucesivas y su duración aproximada es de seis meses para cada una de ellas.

\subsection{Constitución del grupo de análisis}

Para hacernos una idea de la estructura de la actividad que exponemos a los trabajadores, comenzamos por un periodo de observación de las situaciones de trabajo. Cuidamos mucho el modo de exposición ya que la conclusión a la que llegamos no puede ser sino parcial. Nuestro objetivo en esta fase no es llegar a una concepción definitiva, sino mantener abierta la discusión entre los trabajadores de manera tal que no lleguen a considerar que han agotado todas las posibilidades de cuestionar la actividad. Lo que hemos entendido observando el trabajo puede servir de instrumento para el análisis conjunto, siempre que mantengamos un espacio para la controversia. Nuestra finalidad es subvertir el dispositivo de observación de forma tal que los trabajadores sean los observadores de su actividad, en vez de ser los observados.

La primera fase finaliza con éxito cuando los miembros del grupo sienten la necesidad de recurrir a la grabación de las huellas de su actividad para documentar las discusiones. Para ello filmamos a los miembros del grupo, todos voluntarios, durante su trabajo habitual. Si bien son cuatro trabajadores, (o seis como mucho, pero siempre un número par) seleccionados por sus compañeros, todos participan en la selección de los segmentos de trabajo que filmará el equipo de intervención, ya que es una oportunidad para volver a discutir las primeras interpretaciones de la situación de trabajo. Cada filmación dura entre 30 y 45 minutos sin interrupción. Es importante filmar dos o cuatro situaciones similares para facilitar la tarea de comparar las distintas maneras de trabajar.

\subsection{Las autoconfrontaciones: compartir las experiencias}

La segunda fase de la intervención moviliza a los cuatro o seis trabajadores seleccionados por sus compañeros, junto al equipo de intervención. Durante, aproximadamente, los seis meses que dura esta fase se realizan todas las grabaciones de vídeo y los montajes que se utilizarán en la fase posterior. Empezamos por la grabación de la actividad en la que será importante evitar que nadie del entorno profesional, compañeros o jefes, preparen o modifiquen las condiciones de trabajo. Asimismo, es importante que las tareas filmadas sean idénticas en un binomio para comparar las distintas formas de trabajar entre los miembros del grupo, ya que la comparación será la base para debatir acerca de estas diferentes modalidades de trabajo.

Luego de filmar la actividad, y sin dejar pasar más de ocho o diez días, invitamos al trabajador a desplazarse hasta nuestro laboratorio donde filmamos la entrevista que le hacemos. A esta la llamamos entrevista de auto-confrontación directa dado que solicitamos los comentarios directos del trabajador, sin la presencia de ninguno de sus compañeros. La entrevista dura aproximadamente una hora.

Por cuestiones de comodidad de uso, utilizamos un ordenador para proyectar las imágenes. Antes de iniciar la proyección le damos al sujeto la siguiente consigna: siempre que compruebe en las imágenes un quehacer inhabitual o sorprendente, ha de parar la proyección para comentar lo que ve. El comentario puede 
ser espontáneo o responder a una pregunta del investigador. En el curso de la entrevista prestamos mucha atención al lenguaje y a la afectación del trabajador para identificar los momentos que podemos suponer, corresponden a un desarrollo del pensamiento. Cuando ocurren, prestamos atención de no facilitarle la narración ya que, en este contexto, interpretamos las dificultades discursivas como una manifestación externa de la intensidad de la elaboración mental.

Durante la autoconfrontación directa, el trabajador intenta explicar al investigador lo que en la pantalla se le ve hacer. Para conseguirlo necesita describir el contexto de sus acciones. Es decir, detallar lo que no es visible. Al principio de la entrevista, las descripciones están orientadas hacia el investigador. Sin embargo, los análisis de la conversación que hacemos sistemáticamente luego de la autoconfrontación, nos demuestran que las incomprensiones del investigador provocan nuevas orientaciones de los enunciados del trabajador hacia otros destinatarios, aunque no estén físicamente presentes. Pueden ser compañeros del grupo, de taller o de oficio. Incluso pueden ser compañeros que han dejado de ejercer, pero cuyo recuerdo vive aún en la memoria del grupo profesional. Pero además, como señala Bajtín

[...] el autor del enunciado supone la existencia de un destinatario superior (un tercero), cuya comprensión de una respuesta absolutamente justa se sitúa ya sea en un espacio metafísico, o en un tiempo históricamente lejano. (El destinatario para una escapatoria.) [...]. (BAJTÍN, 1982, p. 318-319)

Hemos llegado a la conclusión de que la movilización subjetiva en el trabajo está orientada hacia un destinatario superior, o sea, siendo fieles al concepto de Bajtín, hacia algo más y no solo hacia alguien más. Ese algo al que nos referimos es la historia transpersonal del oficio.

La auto-confrontación indirecta reúne los dos trabajadores del mismo binomio y al investigador. Grabamos la totalidad de la entrevista con mucho cuidado porque, en general, son las imágenes que utilizaremos en la última fase de la intervención. Presentamos el video de la actividad del primer trabajador y solicitamos los comentarios del segundo acerca de la manera de actuar de su compañero. En la segunda parte de la entrevista presen- tamos la actividad del segundo y solicitamos los comentarios del primero. Si el trabajador que ve su propia actividad en la pantalla discrepa con los comentarios de su compañero acerca de su forma de trabajar, puede intervenir y entablar la discusión. Nuestra meta es hacer lo posible por provocar y/o mantener las discrepancias entre los dos trabajadores, cuidando que el objeto de la controversia no deje de ser en ningún momento el trabajo. Es difícil mantener la controversia mucho tiempo sin perder su objeto porque en situaciones tan expuestas los sujetos suelen movilizar sus defensas individuales. Sin embargo, el cuadro dialógico propio de este método nos permite intentarlo con un cierto éxito. Los participantes se dirigen al investigador, cuyo esfuerzo está totalmente orientado a mantener abierta la discrepancia apoyando alternativamente el punto de vista del trabajador que peligra ceder en la discusión. Llega el momento en que los dos dejan de dirigirse al investigador para emprender la discusión entre ambos y tomar como testigo y juez de su discrepancia profesional al colectivo de trabajo.

El análisis de los trabajadores entra así en una nueva fase que consiste en evaluar el estilo de las acciones de cada cual respecto del género profesional. El que comenta las imágenes de su compañero, para contestar las preguntas voluntariamente ingenuas del investigador, imagina lo que hubiese podido hacer en su lugar. De esta manera peligra que sus propias imágenes proyectadas más tarde, en la segunda parte, digan lo contrario de lo que imagina. Circunstancia que aprovechará el investigador para intensificar la controversia profesional entre ambos. Interpretamos la existencia de tales controversias como el desarrollo de la toma de conciencia en el sentido que Vygotski (1993) confiere a este concepto de la psicología, concibiéndola como un modo de generalización dado que percibir las cosas de otro modo es adquirir otras posibilidades de acción con relación a ellas. Generalizar un proceso es transformarlo en una nueva posibilidad para la actividad.

\subsection{Extensión del trabajo de análisis al colectivo de trabajo}

Durante la última fase de la intervención presentamos al grupo inicial un montaje de las secuencias más significativas de las distintas 
controversias profesionales que hemos podido grabar. Tanto el montaje como las imágenes utilizadas cuentan con el acuerdo de los trabajadores que han participado en el proceso de autoconfrontaciones. El objetivo en esta fase es que el colectivo se adueñe del trabajo de sus compañeros como una herramienta para enriquecer las discrepancias. Los desacuerdos surgidos en la fase anterior adquieren nuevas significaciones, incluso para sus autores. El esfuerzo del equipo de intervención es mantener viva las discusiones del oficio como medio de vivificar el género profesional. Es nuestra forma de ayudar a los esfuerzos de los trabajadores para ampliar su poder de acción sobre las cosas y el mundo, con el objetivo de conseguir hacer un trabajo eficiente y de calidad.

En cierto modo es la fase más importante porque organiza una percolación de la experiencia profesional gracias a la discusión de situaciones estrictamente delimitadas. Transforma la acumulación de las experiencias locales en recursos para el colectivo de trabajo y cada uno de sus miembros. Solemos describir esta percolación como un ciclo entre los que hacen los trabajadores, lo que dicen de lo que hacen, y finalmente, lo que hacen de lo que dicen. En este proceso, la actividad dirigida en sí pasa a ser actividad dirigida para sí. La clase de análisis que hacemos con los trabajadores asociados a nuestra investigación, es para ellos una posible elaboración estilística que les permite vitalizar el género profesional en todas sus variantes.

\section{Conclusión}

Hemos presentado una metodología orientada hacia el crecimiento del poder de acción de los colectivos de trabajo. La manifestación más clara de este poder es la creación por los trabajadores de nuevos objetivos para su actividad y de las herramientas para poder alcanzarlos. De esta manera, el trabajo se hace más eficiente y cobra un sentido más personal para su autor. Además de sostener la actividad reflexiva del colectivo, este tipo de análisis del trabajo nos permite construir el objeto de nuestra actividad científica.

Nuestro enfoque no es la mera reivindicación de la experiencia vivida. La dinámica de la vida subjetiva supone poder deshacerse de la experiencia propia para transformarla en un recurso con el fin de vivir nuevas experiencias. Tal como postula Vygotski (1993), pensamos que tomar consciencia no es descubrir un objeto mental momentáneamente inasequible sino crear de nuevo el objeto, que pasa a ser conciente dentro de un contexto nuevo. Tomar conciencia equivale a desarrollar el objeto mental. Es una reconversión que lo inscribe en otra historia. Para el sujeto, el pasaje de objeto a medio para vivir otra experiencia es una migración que permite separar el objeto de la actividad anterior, confiriéndole las propiedades del nuevo contexto. Tomar conciencia es hacer vivir de nuevo el pasado en la acción presente como una posibilidad hasta entonces no realizada. Es sentir que la actividad real integra la totalidad de las opciones posibles de la acción, realizadas o no.

Por consiguiente, en los diálogos profesionales que organizamos nunca tiene sentido pronunciar la última palabra, o ejecutar el último acto. Partiendo de la actividad realizada, nuestro empeño es que los profesionales descubran lo que hubiera podido ser. Es decir, volver a confrontarse al atajo de posibilidades y a los criterios de la decisión. Para ello, es necesario conceptualizar la actividad como una realidad que va más allá de lo visible y de lo inmediato, reconociendo que lo realizado no encierra más que una ínfima parte de lo real. La actividad impedida, diferida, o inhibida, sigue actuando en una unidad desarmónica con las actividades realizadas. Solo la actividad real es responsable de lo nuevo e inesperado en su desarrollo, incluido su posible estancamiento.

La metodología que presentamos no es disociable de la clínica de la actividad que practicamos. Como metodología resulta ser tanto el núcleo de la renovación que proponemos para el análisis del trabajo, como una contribución a un enfoque de la salud en tanto poder de acción sobre el mundo y sobre sí mismo (CLOT, 1999b). 


\section{Referencias}

BAJTIN, M. Estética de la creación verbal. Madrid: Siglo XXI, 1982.

BERTHOZ, A. Le sens du mouvement. Paris: Ed. Odile Jacob, 1997.

CANGUILHEM, G. Le normal et le pathologique. Paris: PUF, 1984.

CLOT, Y. Le travail sans I'homme ? Pour une psychologie des milieux de travail et de vie. Paris: La Découverte, 1995.

CLOT, Y. La fonction psychologique du travail. Paris: PUF, 1999a.

CLOT, Y. Le normal et le pathologique en psychologie du travail. Communication au Colloque G. Canguilhem, Ecole Normale Supérieure de Cachan, Cachan, France, 1999b.

CLOT, Y. El trabajo sin el hombre? Para una psicología de los medios de trabajo y de vida. Madrid: Modus Operandi, 2007 (Publicación pendiente)

CLOT, Y.; FAÏTA, D. Genres et styles en analyse du travail: concepts et méthodes. Travailler : Revue Internationale de Psychopathologie et de Psychodynamique du Travail, Paris, n. 4, p. 7-42, 2000.

CLOT, Y.; FERNANDEZ, G. Mobilisation psychologique et développement du «métier». In : LEMOINE, G. (Ed.) Traité de psychologie et des organisations. Paris: Dunod, 2000. P. 323-342.

FAÏTA, D. La conduite du TGV: exercices de styles. Champs Visuels, Paris, n. 6, p. 75-86, 1997.

LEPLAT, J.; HOC, J.-M. Tâche et activité dans I'analyse psychologique des situations. Cahiers de psychologie cognitive, Marseille, v. 3, n. 1, p. 49-63, 1983.

VYGOTSKI, L. La conciencia como problema de la psicología del comportamiento. In: VYGOTSKI, L. Obras Escogidas. Madrid: Vizor, 1991. V. 1, p. 39-60.

VYGOTSKI, L. La psique, la conciencia, el inconciente. In: VYGOTSKI, L. Obras Escogidas. Madrid: Vizor, 1991. V. 1, p. 95-110.

VYGOTSKI, L. Pensamiento y lenguaje. In: VYGOTSKI, L. Obras Escogidas. Madrid: Vizor, 1993. V. 2, p. 9-348.

Recebido em agosto de 2010.

Aprovado para publicação em agosto de 2010.

\section{Gabriel Fernández}

Conservatoire National des Arts et Métiers - Paris - França.

Email: fernandez@cnam.fr

Yves Clot

Conservatoire National des Arts et Métiers - Paris - França.

Email: clot@cnam.fr 